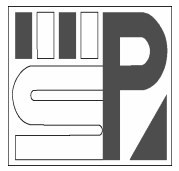

Science Press
Journal of Arid Land

2011, 3(4): 285-291

doi: 10.3724/SP.J.1227.2011.00285

jal.xjegi.com; www.chinasciencejournal.com

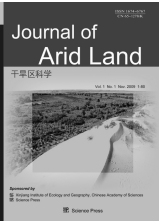

\title{
Application of stable isotope techniques to the study of soil salinization
}

\author{
YongQin CUI ${ }^{1}$, JianYing MA ${ }^{1 *}$, Wei SUN ${ }^{2}$ \\ ${ }^{1}$ Dunhuang Gobi and Desert Ecology and Environment Research Station, Cold and Arid Regions Environmental and Engi- \\ neering Research Institute, CAS, Lanzhou 730000, China; \\ ${ }^{2}$ Key Laboratory of Vegetation Ecology, Ministry of Education, Institute of Grassland Sciences, Northeast Normal University, \\ Changchun 130024, China
}

\begin{abstract}
In this paper, we reviewed the progress in the application of stable isotope techniques to the study of soil salinization. As a powerful technique, stable isotopes have been widely used in the studies of soil water evaporation, the dynamics of soil salinization and salt-tolerant plant breeding. The impact of single environmental factors on plant isotope composition has been the focus of previous studies. However, the impact of multiple environmental factors on plant isotope composition remains unclear and needs to be carefully studied. In order to gain insights into soil salinization and amelioration, especially soil salinization in arid and semiarid areas, it is essential to employ stable isotope techniques and combine them with other methods, such as located field observation and remote sensing technology.
\end{abstract}

Keywords: stable isotope; soil water evaporation; soil salinization dynamic; salt-tolerant plants breeding

Soil salinization is the accumulation of water-soluble salts in the topsoil, or regolith, which impacts agricultural production, environmental health, and economic welfare. Soil salinization is a serious environmental problem in many arid and semi-arid regions of the world (Huang, 2000; Dong et al., 2005). Salinization is a common phenomenon of land degradation, influenced by such factors as climate conditions, soil parent material, water table, soil salinity, etc. In recent years, with a growing world population, there has been an increase in magnitude and intensity of salt-affected soils due to unreasonable irrigation methods, overuse of chemical fertilizer, severe deforestation, etc. It is estimated that tens of millions of hectares of land are degraded every year (Sanders, 2000). Soil salinization has attracted the attention of the government and scientists of many countries. At present, field observation has been widely used to study the physical and chemical properties of saline soil (Li et al., 2004; Feng et al., 2007; Lin and Dilbar, 2007; Zhang and Feng, 2009), the transport features of soil water and salt (Jiang et al., 2006; Yu and Rui,
2007), the driving mechanisms of salinization (Zhang, 1993; Li, 2000; Tian, 2000; Fan et al., 2001; Zhang and Wang, 2002; Ren and Xu, 2003; Chen et al., 2007; Mamat et al., 2008; Zhao et al., 2008; Guan et al., 2009; Wang et al., 2009) and soil amelioration (Yu and Chen, 1994; Zhang and Wang, 1997; Li et al., 1999; Li et al., 2005; Liu et al., 2005; Li et al., 2006; Yu et al., 2009)

As one of the most powerful tools used in ecological and environmental sciences, many stable isotope methods have been used to monitor the ecological process at different spatial and temporal scales, or address issues that are intractable using other methods. Currently, stable isotope methods are widely used in plant physiology (Metzner, et al., 2010), zoology (Graves and Romanek, 2009) and microbial ecology (Bombach et al., 2009) to do scientific research ranging from the molecular level to the entire ecosystem (Lin, 2010). In this paper, we briefly review the pro-

\footnotetext{
Received 2011-07-04; accepted 2011-07-11

*Corresponding author: JianYing MA (E-mail: jyma@lzb.ac.cn)
} 
gress of the application of stable isotope techniques to the study of soil salinization, including the causes of soil salinization, soil salinization dynamic (Yang et al., 2006) and salt-tolerant plants breeding (Poss et al., 2000). Finally, we make some suggestions for the use of stable isotope techniques to study saline soil.

\section{Stable isotopes: an introduction}

Stable isotopes are nonradioactive atoms whose nuclei contain the same number of protons but a different number of neutrons. The major elements used in environmental studies include carbon, hydrogen, oxygen, nitrogen and sulfur. Isotopes behave similarly to these elements. However, certain differences exist in physico-chemical properties due to mass differences. These differences can lead to considerable separation of isotopes during the physical process and chemical reaction (Lin and Ke, 1995). Isotope effects are categorized primarily in two types; equilibrium fractionation and kinetic fractionation. Equilibrium isotope fractionation occurs during isotope exchange reactions that convert one phase (e.g., liquid) to another phase (e.g., vapor). Kinetic isotope fractionation occurs when the reaction is unidirectional and the reaction rates are sensitive to atomic mass at a particular position in one of the reacting species. Isotope effects are usually expressed in terms of delta $(\delta)$ values or discrimination values $(\Delta)$. Isotopic composition $(\delta)$ of a sample is an isotope ratio compared to a standard,

$$
\delta X(\%)=\left(R_{\text {sam }} / R_{\text {std }}-1\right) .
$$

Where, $\delta X$ is the isotope ratio in delta units relative to a standard, and $R_{\text {sam }}$ and $R_{\text {std }}$ are the absolute isotope ratios of the sample and standard, respectively. Discrimination value $(\Delta)$ is the deviation of $\alpha$ from unity,

$$
\Delta=\alpha-1 \text {. }
$$

Where, $\alpha$ is a fractional factor (Mckinney et al., 1950).

\section{Application of stable isotope tech- niques to the study of soil saliniza- tion}

\subsection{Stable hydrogen and oxygen isotopes and evapotranspiration}

Low rainfall and high evaporation lead to soil salinization in arid and semi-arid areas, and high evaporation affects the soil water-salt transport process di- rectly (Qi et al., 1997; Zhang et al., 2008). High evaporation brings the salt to the ground surface with the aid of a capillary force, and then the salt stays in the ground surface and the shallow earth due to low leaching.

The application of hydrogen and oxygen stable isotopes to the study of soil moisture evaporation rule dates back to the 1960s. Zimmermann et al. (1967) first described deuterium isotope concentration in the saturated uniform sandy soil water on the condition that the soil evaporation in steady state has a constant temperature. The results show that the maximum deuterium isotope concentration occurs near the ground surface and decreases exponentially with increasing soil depth. Moreover, Barnes and Allison (1983) studied the motion model of the hydrogen and oxygen stable isotopes in evaporation of unsaturated soil under steady-state conditions and constant temperature, and found that the hydrogen and oxygen stable isotopes concentration increased with the soil depth until the evaporation front and then decreased exponentially, being similar to the above hydrogen and oxygen stable isotopic profile line, and that isotopic depletion might appear below the evaporation front under steady-state conditions and inconstant temperature (Barnes and Allison, 1984). Moreover, in the field, the soil evaporation is not steady-state in most cases. By the late 1980s, Walker et al. (1988) demonstrated that the motion of hydrogen and oxygen stable isotopes in unsaturated soil under unsteady-state conditions follow the energy conservation equation and mass conservation equation, and divided the soil evaporation into two stages: (1) soil stable isotopic profile began to shape when the evaporation rate was constant; (2) topsoil became dry when evaporation ratio decreased, and was in proportion to the square root of time; the accumulation evaporation increased, and was in inverse proportion to the square root of time.

A large number of researches of hydrogen and oxygen stable isotopes were conducted by domestic scholars. For example, Hu et al. (2008) considered surface evaporation, the most important reason for isotope enrichment in soil water after modeling the isotopic profile spread in saturated or unsaturated soil with the evaporation-fractionation model of soil isotope. Wang et al. (2010) presented evaporation as the main cause, which led to the fractionation of stable 
isotopes in soil water based on both Fick's law and mass conservation law.

Overall, the evaporation ratio of soil water in relation to the hydrogen and oxygen isotope discrimination, i.e. the hydrogen and oxygen isotope abundance increases with the increase of the evaporation rate. In addition, varing salinization degrees and types have different effects on the moisture dynamics in topsoil, which allows us to investigate the moisture dynamic mechanism and its effect on the salinization formation.

\subsection{Stable isotopes and soil salinization}

The change of $\delta^{13} \mathrm{C}$ in soil carbonates or plants may reflect the soil salinization degree (Robert et al., 1980; Yang et al., 2006). Farquhar et al. (1989) reported that $\delta^{13} \mathrm{C}$ increased with rising salinization degree whether the plant is halophyte or not, which was also proven by Yang et al. (2006). So the quantified categorization of salinization soil might proceed with the researches.

Salinization is a dynamic process (Yang et al., 2006). The decrease of vegetation cover resulting from unreasonable human activities, i.e. over-clearing land, overgrazing, and denudation, aggravates evaporation in the topsoil, resulting in salt accumulation in the ground surface. During the dynamic process, the decrease of carbon dioxide with ${ }^{12} \mathrm{C}$, and the increase of salts leads to carbon isotope fractionation of soil carbonate, resulting in the increase in soil $\delta^{13} \mathrm{C}$ (Fig. 1). Hence, $\delta^{13} \mathrm{C}$ values of soil carbonate reflects the changeable process and trend, with a positive relationship between the degree of salinization and $\delta^{13} \mathrm{C}$ values of soil carbonate. Finally, by using $\delta^{13} \mathrm{C}$ value in soil carbonate as an indicator to study salinization, we can understand a more objective and precise dynamic process of salinization.

\subsection{Stable isotopes and breeding salt-tolerant plants}

Plant growth in salt-affected land is frequently limited by high salt content, which is one of the major abiotic factors affecting crop yield in arid and semiarid areas (Shaheen and Hood-Nowotny, 2005). With the reduction of arable land, scientists have used various methods to ameliorate the saline soil, including effective land and water resource management practices and chemical ameliorations. However, these measures are expensive and the salinization recurs often. Biological ameliorations, especially salt-tolerant plant breeding, have become a research hotspot in recent years ( $\mathrm{Li}$ et al., 2003; Zhao and Fan, 2005; Lv et al., 2010), which is of great importance to soil amelioration. Stable isotope methods have also been applied to screening salt-tolerant plants.

\subsection{1 $\delta^{13} \mathrm{C}$ and salt stress}

The effect of salt stress on plants is mainly in the inhibition of plant growth by restricting photosynthesis. Stomatal closure is typically associated with increased salinity. Thus, the photosynthesis rate decreases while the salinity is higher than the optimum level (Sibole et al., 1998; Wang et al., 2009). There is a negative correlation between $\delta^{13} \mathrm{C}$ value of plant and $\mathrm{CO}_{2}$ mole fraction in the intercellular air space for plants growing under different saline envrionments (Wei et al., 2008). Therefore, $\delta^{13} \mathrm{C}$ value of plant can be used to reflect the magnitude of salt stress.

Foliar $\delta^{13} \mathrm{C}$ values of $\mathrm{C}_{3}$ plants have also been used as an integrated measure of the response of photosynthetic gas exchange to environmental variables such as salinity (Guy et al., 1986). Farquhar et al. (1982) observed that $\mathrm{C}_{3}$ halophytes growing at high salinity and low water potential had less negative $\delta^{13} \mathrm{C}$ values, which was due to the decreasing of $\mathrm{C}_{\mathrm{i}} / \mathrm{C}_{\mathrm{a}}$, the ratio of intercellular and ambient $\mathrm{CO}_{2}$ partial pressures. Qian et al. (2004) evaluated leaf carbon isotope discrimination as affected by salinity among three Kentucky bluegrass (Poa pratensis L.) cultivars that differ in their salt tolerance, and concluded that salinity induced a greater degree of stomatal resistance that provided less opportunity for discrimination against the heavier isotope. Shaheen and Hood-Nowotny (2005a; $2005 b)$ achieved similar results through measuring $\delta^{13} \mathrm{C}$ values of rice and wheat cultivars in different levels of salinity. In summary, salinity leads to a reduction in photosynthetic carbon isotope discrimination $(\Delta)$, and subsequently, an increase in $\delta^{13} \mathrm{C}$ values. However, opposite conclusions were also reported by Chen et al., (2004). Clough and Sim (1989) suggested that with increasing salinity, maximum photosynthesis and water use efficiency (WUE) of some mangrove plant species decreased, which are positively correlated with $\delta^{13} \mathrm{C}$ values. The relationship between $\delta^{13} \mathrm{C}$ values and salinity is relevant to intrinsic salt-tolerance, 


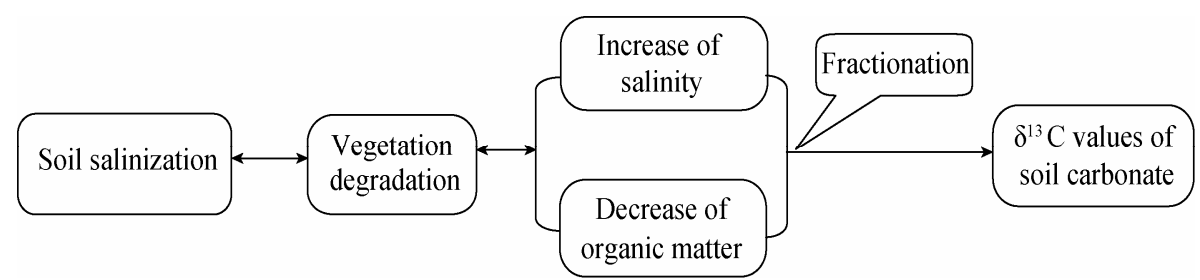

Fig. 1 Relationship between the carbon isotope compositions $\left(\delta^{13} \mathrm{C}\right)$ of soil carbonates and soil salinization

salinity level and the growth period of plant species under saline conditions (Wei et al., 2008).

Relatively little information is available concerning the effects of salinity on photosynthetic gas exchange and carbon isotope compositon in $\mathrm{C}_{4}$ herbs (Meizer et $a l .$, 1994). Previous research has found that increasing soil salinity resulted in a decreased photosynthesis in the $\mathrm{C}_{4}$ plants. A concomitant increase in $\mathrm{O}_{2}$ sensitivity to photosynthesis and a decrease in $\delta^{13} \mathrm{C}$ of leaves were also measured with increasing salinity. The results suggest that an increase in the leakage of $\mathrm{CO}_{2}$ out of, and $\mathrm{O}_{2}$ into the bundle sheath under saline conditions, led to an increase in the proportion of ${ }^{13} \mathrm{C}$ discriminated by RuBP carboxylase (Bowman et al., 1989). By measuring carbon isotope discrimination, and gas exchange, Meinzer et al. (1994) suggested that variation in $\delta^{13} \mathrm{C}$ value was attributed largely to the variation in bundle sheath leakiness to $\mathrm{CO}_{2}(\varphi)$. Salinity-induced increases in $\varphi$ appeared to be caused by a reduction in the $\mathrm{C}_{3}$ pathway activity relative to $\mathrm{C}_{4}$ pathway activity (Meinzer et al., 1994). According to former research, there is a negative correlation between the $\delta^{13} \mathrm{C}$ value of the $\mathrm{C}_{4}$ plant and salinity. Further research is clearly needed on both the mechanisms of stress-induced adjustments in photosynthesis and on the extent of which the $\delta^{13} \mathrm{C}$ values in $\mathrm{C}_{4}$ plant is influenced by the increase in the leakage of $\mathrm{CO}_{2}$.

2.3.2 $\quad \delta^{13} \mathrm{C}$ and breeding salt-tolerant plants

There are two main mechanisms of plant salinity tolerance. One mechanism is to prevent salt injury through salt exclusion, salt rejection and salt dilution; another is to endure the saline environment by changes in plant characteristics, including osmotic stress-tolerance, balance of elements and stability of the metabolism (Cheeseman, 1988; Yang et al., 2002). So breeding salt-tolerant plants can improve the salt-tolerant plants, taking full advantage of the saline soil (Wang, 2007) and increasing the crop yield. Stable isotope techniques can be applied to the selection of a salt-tolerant species.

As mentioned above, foliar $\delta^{13} \mathrm{C}$ values have been used as an integrated measure in the response of photosynthetic gas exchange to environmental variables such as soil water availability, light, humidity and salinity. Thus, $\delta^{13} \mathrm{C}$ value may serve as a useful selection criterion in breeding efforts to develop salt tolerant plants. When screening salinity tolerance in rice at the seedling stage, there was a significant negative relationship between the $\Delta$ value and the salt stress of rice, which indicated that a high $\Delta$ value could be used as a physiological indicator for screening the tolerant cultivars of rice (Shaheen and Hood-Nowotny, 2005a). The study of Meinzer et al. (1994) showed that the $\mathrm{CO}_{2}$ assimilation rate (A), stomatal conductance $\left(\mathrm{g}_{\mathrm{s}}\right)$ and shoot growth rate (SGR) of sugarcane began to decline as electrical conductivity (EC) of the irrigation solution increased above $2 \mathrm{dS} / \mathrm{m}$. A, $\mathrm{g}_{\mathrm{s}}$, and SGR of a salt-resistant cultivar were consistently higher than those of a salt-susceptible cultivar at all levels of salinity and declined less with increasing salinity. The $\delta^{13} \mathrm{C}$ value in tissues obtained from the uppermost fully expanded leaf decreased with salinity. Therefore, the $\delta^{13} \mathrm{C}$ value may be used as an indicator for $\mathrm{A}, \mathrm{g}_{\mathrm{s}}$ and SGR and for screening salt-tolerant sugracane. Qian et al. (2004) reported that salinity induced a greater degree of stomatal resistance that provided less opportunity for discrimination against the heavier isotope, and carbon isotope discrimination is a useful criterion for screening salt-tolerant Kentucky bluegrass cultivars. It was also concluded that the $\delta^{13} \mathrm{C}$ value may prove to be a useful index for selecting wheat cultivars with improved harvest index in salt-affected areas (Shaheen and Hood-Nowotny, 2005b).

\section{Conclusion and suggestions}

Stable isotope technology has started to show its great potential as a powerful tool in researching saline soil formation mechanism and breeding salt-tolerant plants. 
The $\delta^{13} \mathrm{C}$ value can reflect the developing tedency of soil salinization and indicate the effects of salt stress on plants, and can be used as a useful indicator for screening salt-tolerant plants. In the meantime, stable isotope technology has some defects during the application process. For example, the cost of sample analysis is expensive because the mass spectrometer used to obtain isotopic ratios, needs to be professionally operated. Currently, the application of stable isotope technology on the study of soil salinization has little field experimentation, and is still in the theorectically stage. Therefore, we have the following suggesitons for the use of isotopes to research saline soils.

(1) The application of stable isotopes to the study of soil salinization is a process from simple to complex and from monofactor to multifactor. One of its development trends is to analyze the effects of multiple environmental factors, such as temperature (O'leary, 1981), light (Yin et al., 2008), precipitation (Sun et al., 2003), atmospheric $\mathrm{CO}_{2}$ concentration (Feng and Epstein, 1995), altitude (Chen et al., 2003), latitude and altitude (Ma et al., 2005), as well as regional background. The regionalization and comprehensiveness of the study on saline soil help to improve prediction, to mornitor the dynamics of soil salinizaton, and is an important basis of soil am-

\section{References}

Barnes C J, Allison G B. 1983. The distribution of deuterium and oxygen-18 in dry soils: 1 . Theory. Journal of Hydrology, 60(1-4): $141-156$.

Barnes C J, Allison G B. 1984. The distribution of deuterium and ${ }^{18} \mathrm{O}$ in dry soils: 3 . Theory for non-isothermal water movement. Journal of Hydrology, 74(1-2): 119-135.

Bombach P, Chatzinotas A, Thomas R N, et al. 2009. Enrichment and characterization of a sulfate-reducing toluene degrading microbial consortium by combining in situ microcosms and stable isotope probing techniques. FEMS Microbiology Ecology, 71(2): 237-246.

Bowman W D, Hubick K T, Caemmerer von S, et al. 1989. Short-term changes in leaf carbon isotope discrimination in salt and water stressed $\mathrm{C}_{4}$ grasses. Plant Physiology, 90: 162-166.

Cheeseman J M. 1988. Mechanism of salinity tolerance in plant. Plant Physiology, 87: 541-550.

Chen T, Yang M X, Feng H Y, et al. 2003. Spatial distribution of stable carbon isotope compositions of plant leaves in the north of the Tibetan Plateau. Journal of Glaciology and Geocryology, 25(1): 83-87.

Chen X B, Yang J S, Liu C Q. 2007. Study on soil secondary salinization and related issues in Alar Irrigation Area, Xinjiang. Journal of Arid Land Resources and Environment, 21(6): 168-172. elioration.

(2) It is beneficial to resolve the scientific issues if combining the isotopes with other methods, such as field investigaton or remote sensing (Jiang et al., 2008; Wang and Tashpolat, 2009). Combining stable isotope techniques with other branch fields of ecology is conducive to exploring the cycling of matter at the terrestrial ecosystem level and the process of vegetation degradation. For instance, soil salinization can be researched by using hydrogen and oxygen stable isotopes (Wang et al., 2008) while understanding the relationship between soil water and soil salinity (Li et al., 2000).

(3) It is necessary to seek the substitution indices of $\delta^{13} \mathrm{C}$, because the system is quite expensive.

(4) The relationship between isotope discrimination and the stress-induced physiological changes in plants of growing under different degrees of salinity need to be established. Thus, sampling numerous plants under salinity stress conditions in different geographic units and climate conditions are necessary.

\section{Acknowledgements}

This research was supported by the National Basic Research Program of China (2009CB825101), the National Natural Science Foundation of China (41071032) and the West Light Foundation of the Chinese Academy of Sciences (2009).

Chen Y H, Hu J, Li Y H, et al. 2004. Application of stable carbon isotope techniques to research into water stress. Acta Ecologica Sinica, 24(5): 1027-1033.

Clough B F, Sim R G. 1989. Changes in gas exchange characteristics and water use efficiency of mangroves in response to salinity and vapor pressure deficit. Oecologia, 79(1): 38-44.

Dong X G, Deng M J, Zhou J L, et al. 2005. On exploitation of water resources and soil salinization in irrigation area of Xinjiang plain. Journal of Irrigation and Drainage, 24 (5): 14-17.

Fan Z L, Ma Y J, Ma Y J. 2001. Salinized soils and their improvement and utilization in West China. Arid Zone Research, 18(3): 1-6.

Farquhar G D, Ball M C, von Caemmerer S, et al. 1982. Effect of salinity and humidity on $\delta^{13} \mathrm{C}$ value of halophytes-evidence for diffusional isotope fractionation determined by the ratio of intercellular/atmospheric partial pressure of $\mathrm{CO}_{2}$ under different environmental conditions. Oceologia, 52: 121-124.

Farquhar G D, Ehleringer J R, Hubick K T. 1989 Carbon isotope discrimination and photosynthesis. Annual Review of Plant Physiology, 40: 503-537.

Feng X H, Epstein S. 1995. Carbon isotopes of trees from arid environments and implications for reconstructing atmospheric $\mathrm{CO}_{2}$ 
concentration. Geochimica et Cosmochimica Acta, 59: 2599-2608.

Feng Y J, Zhang W, Chen Q, et al. 2007. Physico-chemical characteristics and microbial composition of saline-alkaline soils in Songnen Plain. Soils, 39(2): 301-305.

Graves G R, Romanek C S. 2009. Mesoscale patterns of altitudinal tenancy in migratory wood warblers inferred from stable carbon isotopes. Ecological Applications, 19(5): 1264-1273.

Guan F C, Yan C, Liang Z W. 2009. Differences of the soil and vegetation in Phragamites australis community between enclosed and grazed alkali-salinity wetlands. Wetland Science, 7(1): 47-52.

Guy R D, Reid D M, Krouse H R. 1980. Shifts in carbon isotope ratios of two $\mathrm{C}_{3}$ halophytes under natural and artificial conditions. Oecologia, 44: 241-247.

Guy R D, Reid D M, Krouse H R. 1986. Factors affecting ${ }^{13} \mathrm{C} /{ }^{12} \mathrm{C}$ ratios of inland halophytes I. Controlled studies on growth and isotopic composition of Puccinellia nuttalliana. Canada Journal of Botany, 64: 2693-2699.

Hu H Y, Bao W M, Wang T, et al. 2008. Simulation and experiment on variations of hydrogen and oxygen isotopes in soil water. Water Resources and Power, 26(4): 149-152.

Huang C Y. 2000. Pedology. Beijing: China Agricultural Press, 297-305.

Jiang H N, Tashpolat T, Ding J L, et al. 2008. Tempo-spatial change driving forces of land salinization in Weigan Irrigated Area, Xinjiang. Arid Land Geography, 31(6): 885-891.

Jiang S C, Zhou D W, Jin Y H. 2006. Characteristic of moisture and salt dynamic in saline-alkalized grassland of Songnen Plain during thawing period. Journal of Northeast Normal University: Natural Science Edition, 38(4): 124-128.

Li B, Wang Z C, Sun Z G, et al. 2005. Resources and sustainable resource exploitation of salinized land in China. Agricultural Research in the Arid Areas, 23(2): 154-158.

Li J Y, Zhang F C, Ma J, et al. 2003. The mechanisms of salt resistance in plants in molecular levels. Plant Physiology Communications, 39(6): 715-719.

Li Q S, Wu L Z, Liu C J. 2006. Amelioration model of medium saline-alkali soil by leaching with mildly saline groundwater. Agricultural Research in the Arid Areas, 24(4): 164-167.

Li X G, Cao J, Li F M. 2004. Influence of salinity, sodicity and organic matter on some physical properties of salt-affected soils. Chinese Journal of Soil Science, 35(01): 64-72.

Li X J, Zhang Z G, Li Y X, et al. 1999. Effects of straw mulch on saline soil water regime. Journal of Shandong Agricultural University Natural Science Edition, 30(4): 398-403.

Li X J. 2000. The alkili-saline land and agricultural sustainable development of the western Songnen Plain in China. Scientia Geographica Sinica, 20(1): 51-55.

Li X J, Zhang Z G, Liu X L. 2000. Studies effects of soil salt content on soil water evaporation. Journal of Shandong Agricultural University: Natural Science Edition, 31(2): 209-210.

Lin G H, Ke Y. 1995. Stable isotope techniques and global change research. In: Li B. Lectures on Modern Ecology. Beijing: Science Press, $161-188$.

Lin G H. 2010. Stable isotope ecology: a new branch of ecology resulted from technology advances. Chinese Journal of Plant Ecology, 34(2): 119-122.

Lin J, Dilbar S. 2007. Progress in the study on soil salinization. Journal of Xinjiang University: Natura1 Science Edition, 24 (03) : 318-323.

Liu H J, Wang J H, Yang Z H, et al. 2005. The saline soil was improved by engineering techniques. Chinese Agricultural Science Bulletin, 21(4): 329-333.

Lv X F, Li L, Xu X W, et al. 2010. Differences of salt tolerance of four halophytes in salinized desert in the Junggar Basin. Arid Zone Research, 27(1): 97-101.

Ma J Y, ChenT, Qiang W Y, et al. 2005. Correlations between foliar stable carbon isotope composition and environmental factors in desert plant Reaumuria soongorica (Pall.) Maxim. Journal of Integrative Plant Biology, 47(9): 1065-1073.

Mamat G, Alkam K, Tursun K. 2008. The research summary of soil salinization and management. Environmental Science and Management, 33(5): 29-33.

Mckinney C R, McCrea J M, Epstein S, et al. 1950. Improvements in mass spectrometers for the measurement of small differences in isotope abundance ratios. Review of Scientific Instrument, 21: 724-730.

Meinzer F C, Plaut Z, Saliendra N Z. 1994. Carbon isotope discrimination, gas exchange, and growth of sugarcane cultivars under salinity. Plant Physiology, 104: 521-526.

Metzner R, Schneider U H, Breuer U, et al. 2010. Tracing cationic nutrients from xylem into stem tissue of French bean by stable isotope tracers and cryo-secondary ion mass spectrometry. Plant Physiology, 152: 1030-1043.

O'Leary M H. 1981. Carbon isotope fractionation in plants. Phytochemistry, 20(4): 553-567.

Poss J A, Grattan S R, Suarez D L, et al. 2000. Stable carbon isotope discrimination: an indicator of cumulative salinity and boron stress in Eucalyptus camaldulensis. Tree Physiology, 20: 1121-1127.

Qi L X, Chen Q S, Pang C H. 1997. Monitoring and predicting investigation on soil salinisation. Acta Pedologica Sinica, 34(2): 189-199.

Qian Y L, Follett R F, Wilhelm S, et al. 2004. Carbon isotope discrimination of three Kentucky bluegrass cultivars with contrasting salinity tolerance. Agronomy Journal, 96: 571-575.

Ren J G, Xu M. 2003. Research on the relation between salinization of soil and the shaft irrigation and drainage. The Chinese Journal of Geological Hazard and Control, 14(3): 55-57.

Sanders D. 2000. Plant biology: the salty tale of Arabidopsis. Current Biology, 10: 486-488.

Shaheen R, Hood-Nowotny R C. 2005a. Carbon isotope discrimination: potential for screening salinity tolerance in rice at the seedling stage using hydroponics. Plant Breeding, 124(3): 220-224.

Shaheen R, Hood-Nowotny R C. 2005b. Effect of drought and salinity on carbon isotope discrimination in wheat cultivars. Plant Science, 168: 901-909.

Sibole J V, Montero E, Cabot C, et al. 1998. Role of sodium in the ABA mediated long term growth response of bean to salt stress. Plant Physiology, 104: 299-305.

Sun B N, Dilcher D L, Beerling D J, et al. 2003. Variation in Ginkgo 
biloba L. leaf characters across a climatic gradient in China. Proceedings of the National Academy of Sciences (PNAS), 100(12): 7141-7146.

Tian C Y. 2000. The proposal on control of soil salinizing and agricultural sustaining development in the $21^{\text {st }}$ century in Xinjiang. Arid Land Geography, 23(2): 177-181.

Walker G R, Hughes M W, Allison G B, et al. 1988. The movement of isotopes of water during evaporation from a bare soil surface. Journal of Hydrology, 97: 181-197.

Wang B S. 2007. Plant Physiology. Beijing: Science Press, 275-303.

Wang H W, Tashpolat T. 2009. Remote sensing dynamic monitor and driving force of soil salinization in arid area. Arid Land Geography, 32(3): 445-453.

Wang T, Bao W M, Hu H Y, et al. 2008. Application of hydrogen and oxygen stable isotopes in the study of soil evaporation. China Rural Water and Hydropower, (4): 21-25.

Wang W H, Zhang X M, Yan H L, et al. 2009. Effect of salt stress on photosynthesis and osmoregulation substances of Tamarix ramosissima Ledeb. Arid Zone Research, 26(4): 561-568.

Wang X M, Chai Z P, Tashpolat T, et al. 2009. Analysis of soil salinization and influential factors in arid region - a case study in the delta oasis of Weigan and Kuqa Rivers. Soil, 41(3): 477-482.

Wang Y S, Chen J S. 2010. Study of stable isotope model for saturated soil water movement in the condition of evaporation. Journal of Sichuan University: Engineering Science Edition, 42(1): 10-13.

Wei L L, Yan C L, Ye B B, et al. 2008. Relationship between salinity and stable carbon isotope composition of $\mathrm{C}_{3}$ plants. Acta Ecologica Sinica, 28(3): 1270-1278.

Yang J P, Hu K, Liu Y Y. 2006. The stable carbon isotopic characteristics of carbonates in salini-alkani soil in the West Jilin Province. Journal of Jilin University: Earth Science Edition, 36(2): 245-249.

Yang Y H, Sun Q Y, Shen H. 2002. Salt injury and salt resistance of plant. Biology Teaching, 27(11): 1-2.

Yin S P, Zhang C J, Guo F Q, et al. 2008. Effect of environmental factors on stable carbon isotopic composition of plants and application in water use efficiency. Journal of Isotopes, 21(1): 46-53.

Yu M, Rui X F. 2007. Study on integrated management model of groundwater and surface water for prevention of soil salinization. Water Resources Protection, 23(4): 6-9.

Yu R P, Chen D M. 1994. Exploitation and utilization of saline soil resources of China. Chinese Journal of Soil Science, 6(4): 158-159.

Yu S P, Yang J S, Yang X Y. 2009. Impacts of different adjustment measures on quality dynamics of crop and soil in salinization blocked farm land in Huang-Huai-Hai Plain. Journal of Arid Land Resources and Environment, 23(8): 150-154.

Zhang B Q. 1993. Soil salinization and its prevention in Xinjiang. Arid Zone Research, 10(1): 55-61.

Zhang D F, Wang S J. 2002. Study on the eco-geo-environment of land salinization in West Jilin province. Chinese Journal of Soil Science, 33(2): 90-93.

Zhang J H, Wang Q J, Yao X H, et al. 2008. Analysis on the effects of technical parameters of grape drip irrigation on soil salt content distribution in arid areas of Xinjiang. Arid Zone Research, 25(5): 679-682.

Zhang W, Feng Y J. 2009. Physico-chemical properties and ecological recovery of saline-alkaline soil in Songnen Plain. Acta Pedologica Sinica, 46(1): 169-172.

Zhang Y B, Wang X L. 1997. Salt water irrigation in area with a salinized surface soil horizon. Acta Pedologica Sinica, 34(1): 53-59.

Zhao K F, Fan H. 2005. Halophytes and Adaptive Physiology of Saline Soil Environments. Beijing: Science Press.

Zhao Y, Chai Q, Chen Y Y, et al. 2008. Improvement and utilization of saline-alkali grassland in Hexi Corridor. Pratacultural Science, 25(2): 21-25.

Zimmermann U, Ehhalt D, Muennich K O. 1967. Soil water movement and evapotranspiration: changes in isotopic composition of the water. In: Knippner M. Proceedings of IAEA Symposium on Isotope Hydrology. Vienna: Int At. Energy Agency, 567-585. 